Research Paper

\title{
Clinicopathologic Review of Ovarian Masses in Korean Premenarchal Girls
}

\author{
Eun Young Ki ${ }^{1}$, Seung Won Byun ${ }^{1}$, Yoon Jin Choi ${ }^{1}$, Keun Ho Lee ${ }^{1}$, Jong Sup Park ${ }^{1}$, Sung Jong Lee ${ }^{2}$, Soo \\ Young Hur ${ }^{1,}$, \\ 1. Department of Obstetrics and Gynecology, The Catholic University of Korea, Seoul St. Mary's Hospital; \\ 2. Department of Obstetrics and Gynecology, The Catholic University of Korea, St. Vincent Hospital.
}

$\square$ Corresponding author: Soo Young Hur M.D., Ph.D. Professor, The Catholic University of Korea. Departmentof obstetrics and gynecology, Seoul St. Mary's Hospital, \#505 Banpo-Dong, Seocho-Gu, Seoul, Korea. Post code: 137-040 Phone: +82-2-2258-6171, Cell Phone: +82-10-5316-1226 Fax: +82-2-595-1549 E-mail: hursy@catholic.ac.kr.

( ) Ivyspring International Publisher. This is an open-access article distributed under the terms of the Creative Commons License (http://creativecommons.org/ licenses/by-nc-nd/3.0/). Reproduction is permitted for personal, noncommercial use, provided that the article is in whole, unmodified, and properly cited.

Received: 2013.03.08; Accepted: 2013.05.28; Published: 2013.06.21

\begin{abstract}
Objective: To review the clinicopathological characteristics of ovarian masses in Korean premenarchal girls.

Design: The data collected from hospital medical records were reviewed retrospectively regarding age, presentation, diagnosis, treatment, and outcome.

Participants: There were 65 premenarcheal girls who underwent surgery at Seoul St. Mary's Hospital between January 1990 and March 2012.

Results: The most common presenting symptom was abdominal pain $(n=31,47.7 \%)$, followed by palpable abdominal masses $16(n=16,24.6 \%)$, abdominal distension $(n=8,12.3 \%)$, vaginal bleeding $(n=4,6.2 \%)$, incidental finding $(n=3,4.6 \%)$, difficulty in urination or defecation $(n=2,3.1 \%)$, and prenatal sonographic findings $(n=1,1.5 \%)$. Of the patients with benign tumors, including non-neoplastic lesions and benign cysts, $26(5 \mathrm{I} \%)$ underwent cystectomy, $6(1 \mathrm{I} .8 \%)$ underwent oophorectomy, 17 (33.3\%) underwent unilateral salpingo-oophorectomy and none underwent bilateral salpingo-oophorectomy. Of the patients with malignant tumors, 2 (14.3\%) underwent bilateral salpingo-oophorectomy, 7 (50\%) underwent unilateral salpingo-oophorectomy, 2 (14.3\%) underwent oophorectomy, and 2 (14.3\%) underwent cystectomy.

Conclusion: Abdominal pain was the most common symptom. However, the incidence of abdominal distension was higher in patients with malignant tumors than in those with benign tumors. We assessed clinical features, operative outcomes, and histological classifications of Korean prememarchal girls with ovarian masses. Further studies with a larger number of subjects are needed to confirm our results.
\end{abstract}

Key words: premenarchal girl, ovarian mass, clinicopathological observation.

\section{Introduction}

In children, indications for gynecologic surgery are divided into 3 categories: congenital anomalies, genital traumas and pathological lesions of the genital tract. Adnexal lesions are the most common indication for gynecologic surgery in children. Although the frequency of adnexal surgery in children is low, it is important to save patients from death and preserve their fertility.

Ovarian cysts develop from mature follicles in hormonally active ovaries, so that they are often detected after puberty. Ovarian masses, whether cystic, solid or both, are generally considered rare in the 
premenarchal age group [1]. The actual incidence of pediatric ovarian lesions is unknown. However, ovarian neoplasms are estimated to occur at a rate of approximately 2.6 in 100,000 girls per year and malignant tumors make up about $1 \%$ of all childhood malignant tumors [1-3]. Ovarian masses receive surgical interventions for various causes. Most patients have nonspecific symptoms. Patients may present with acute abdominal pain and signs of peritonitis which are difficult to distinguish from acute appendicitis. Patients with ovarian lesions which secrete hormones may present with pseudoprecocity, masculinization or the signs of endocrine disturbances. Some patients may have huge masses, which can cause ureteral obstructions, hydronephrosis, urinary frequency or difficulty, and bowel obstruction [1, 4-6].

There have been many studies on the clinical characteristics of patients who have developed adnexal masses in the pediatric population. However, age criteria vary among the different studies. Therefore, more information about the clinical characteristics of children with adnexal masses is necessary to establish procedures for early diagnoses and to adequately manage such lesions in children. This study analyzed the clinicopathological characteristics of 65 Korean premenarchal girls who underwent surgery at Seoul St. Mary's Hospital due to adnexal masses between January 1990 and March 2012.

\section{Materials and Methods}

This study included 65 premenarchal patients who underwent surgery due to adnexal masses at our hospital between January 1990 and March 2012. Clinicopathological data was retrospectively collected from the patients' hospital medical records. The records were analyzed in terms of demographic characteristics, initial symptoms, complications, surgical methods and histological diagnoses. The study was approved by the Institutional Review Board (KC12RISI0881). All statistical analyses were performed using Student's $t$ test and the Fischer exact test. A $p$ value of $<0.05$ was considered statistically significant.

\section{Results}

In our study, 65 premenarchal girls underwent ovarian tumor surgeries. The mean age of the patients at presentation was 9.6 \pm 3.3 years (range, 0.08-15 years). The most common presenting symptom was abdominal pain $(n=31,47.7 \%)$, followed by palpable abdominal masses $(\mathrm{n}=16,24.6 \%)$, abdominal distension $(n=8,12.3 \%)$, vaginal bleeding $(n=4,6.2 \%)$, incidental finding $(n=3,4.6 \%)$, difficulty in urination or defecation $(n=2,3.1 \%)$, and prenatal ultrasonographic findings ( $\mathrm{n}=1,1.5 \%)$ (Table 1). Three patients' masses were discovered incidentally during appendectomy. These patients were diagnosed with appendicitis or panperitonitis at the Department of Surgery and underwent operations, revealed ovarian masses. There are 2 patients that complained of atypical symptom, such as difficulty in urination or defecation. One patient complained of difficulty in urination, which prompted her visit to our clinic. We checked transabdominal ultrasonography (TAS), which revealed that there was a huge mass in her pelvic cavity and that the bladder was not visible. Computed tomography (CT) showed that there was a huge mass in the pelvic cavity containing fat and calcified material, which was accompanied by right hydronephrosis. The other patient complained of chronic constipation. CT showed a huge pelvic mass containing fat, calcified material, and hair.

One patient's ovarian cyst was discovered via a prenatal sonography when she was at the gestational age of 25 weeks. Ultrasonography performed at the gestational age of 25 weeks revealed ovarian cyst. Ultrasonography performed immediately after birth revealed an ovarian cyst measuring $3.0 \mathrm{~cm}$. Follow-up sonography performed 1 month after the birth revealed a $3.0 \times 3.5-\mathrm{cm}$ ovarian cyst, which was surgically removed. Of the 31 patients who complained of abdominal pain, $24(77.4 \%)$ had ovarian torsion, 1 (3.2\%) had ovarian cyst rupture, and 6(19.4\%) had inflammation or adhered to the adjacent organs (Table 1). This pain was induced by the adhesions to the adjacent organs due to the traction by the masses.

Table I. Initial symptoms and signs at primary initial presentation.

\begin{tabular}{ll}
\hline Initial symptom and sign & No. of patients(\%) \\
\hline Abdominal pain & $31(47.7)$ \\
Abdominal palpable mass & $16(24.6)$ \\
Abdominal distension & $8(12.3)$ \\
Vaginal bleeding & $4(6.2)$ \\
Incidental finding & $3(4.6)$ \\
Difficulty in urination/ defecation & $2(3.1)$ \\
Prenatal ultrasonographic finding & $1(1.5)$ \\
Causes of pain & No. of patients(\%) \\
Torsion & $24(77.4)$ \\
Rupture & $1(3.2)$ \\
Others & $6(19.4)$ \\
\hline
\end{tabular}


Comparisons between the patients with torsion (group 1) and those without torsion (group 2) are shown in Table 2. The mean ages were $9.3 \pm 2.2$ years (range, $4-13$ years) in group 1 and $9.8 \pm 3.8$ years (range, $0.08-15$ years) in group 2 . There were no significant differences in age $(p=0.5136)$. The chief complaint was abdominal pain $(n=24,100 \%)$ in group 1 , while the chief complaints were palpable abdominal masses $(n=16,39 \%)$, abdominal pain $(n=7,17.1 \%)$, prenatal ultrasonographic findings $(n=1,2.4 \%)$ and others $(n=17,41.5 \%)(p<0.0001)$ in group 2 . The mean size of the ovarian cysts was $6.7 \pm 2.7 \mathrm{~cm}$ (range, $2-15 \mathrm{~cm}$ ) in group 1 and $10.6 \pm 6.0 \mathrm{~cm}$ (range, $0.7-22 \mathrm{~cm}$ ) in group 2 . Tumor size was slightly larger in group 2 than in group $1(p=0.0009)$. In group 1,5 patients $(20.8 \%)$ had non-neoplastic lesions, 18 patients $(75 \%)$ had benign tumors, and 1 patient $(4.2 \%)$ had a malignant tumor. In group 2, 2 patients $(4.9 \%)$ had non-neoplastic lesions, 26 patients $(63.4 \%)$ had benign tumors, and 13 patients $(31.7 \%)$ had malignant tumors $(p=0.0063)$. Table 3 shows the histologic types of the ovarian tumors in our series. A small cyst measuring $2.0 \mathrm{~cm}$ was found in a group 1 patient. It was incidentally found by the general surgery team during an operation. The patient complained of nonspecific abdominal pain and was diagnosed with panperitonitis. In the surgical field, the appendix was found to be normal but the right ovary had a $2-\mathrm{cm}$ cyst containing fat and hair. It was twisted $270^{\circ}$ and caused pain. Two non-neoplastic patients were included in group 2. One patient had a $0.7-\mathrm{cm}$ follicular cyst and complained of abdominal pain, and her TAS showed considerable hypoechoic fluid in the pelvic cavity suggestive of hemoperitoneum. Her pathologic diagnosis was follicular cyst. The other patient was also diagnosed with follicular cyst and complained of acute abdominal pain; her TAS showed a 7-cm within homogenous isoechoic cyst. In the surgical field, the hemorrhage was noted within the cyst.

The majority of ovarian masses were benign $(67.7 \%), 7$ ovarian masses $(10.8 \%)$ were non- neoplastic, and 14 ovarian masses $(21.5 \%)$ were malignant (Table 3). The most common type of benign ovarian tumors were dermoid cysts $(64.6 \%$ of all ovarian masses) and the most common type of malignant ovarian tumors were immature teratomas $(7.7 \%$ of all ovarian masses). In our study, there was 1 patient with a corpus luteum. An 11-year-old premenarchal girl visited our clinic due to acute abdominal pain. Transrectal ultrasonography showed a right ovarian cyst and color Doppler revealed no blood flow. A twisted ovarian cyst was found during the operation. Her pathologic diagnosis was a corpus luteal cyst.
Table 2. Comparisons between patients with torsion (group I) and those without torsion (group 2).

\begin{tabular}{|c|c|c|c|}
\hline & $\begin{array}{l}\text { Group } 1 \\
(n=24)\end{array}$ & $\begin{array}{l}\text { Group } 2 \\
(\mathrm{n}=41)\end{array}$ & $P$ value* \\
\hline Age (years), mean $\pm \mathrm{SD}$ (range) & $\begin{array}{l}9.3 \pm 2.2 \\
(4-13)\end{array}$ & $\begin{array}{l}9.8 \pm 3.8 \\
(0.08-15)\end{array}$ & 0.5136 \\
\hline Chief complaint, n (\%) & & & $<0.0001$ \\
\hline Mass & 0 & $16(39.0)$ & \\
\hline Pain & $24(100.0)$ & 7 (17.1) & \\
\hline Prenatal finding & 0 & $1(2.4)$ & \\
\hline Others & 0 & $17(41.5)$ & \\
\hline Size $(\mathrm{cm})$, mean $\pm \mathrm{SD}$ (range) & $\begin{array}{l}6.7 \pm 2.7 \\
(2-15)\end{array}$ & $\begin{array}{l}10.6 \pm 6.0 \\
(0.7-22)\end{array}$ & 0.0009 \\
\hline Oophorectomy, n (\%) & $14(58.3)$ & $23(56.1)$ & 0.8606 \\
\hline Pathology, n (\%) & & & 0.0063 \\
\hline Nonneoplastic lesion & $5(20.8)$ & $2(4.9)$ & \\
\hline Benign & $18(75.0)$ & $26(63.4)$ & \\
\hline Malignant & $1(4.2)$ & $13(31.7)$ & \\
\hline Location, n (\%) & & & 0.1445 \\
\hline Right & $13(54.2)$ & $19(46.3)$ & \\
\hline Left & $11(45.8)$ & $16(39.0)$ & \\
\hline Both & 0 & $6(14.6)$ & \\
\hline
\end{tabular}

Table 3. Pathological diagnoses of the ovarian tumors.

\begin{tabular}{ll}
\hline Pathology & No. of patients (\%) \\
\hline Nonneoplastic lesion & $7(10.8)$ \\
Corpus luteum & $1(1.5)$ \\
Simple/follicular cyst & $6(9.2)$ \\
Benign & $44(67.7)$ \\
Dermoid cyst & $42(64.6)$ \\
Serous cystadenoma & $2(3.1)$ \\
Malignant & $14(21.5)$ \\
Dysgerminoma & $3(4.6)$ \\
Juvenile granulose cell tumor & $2(3.1)$ \\
Yolk sac tumor & $2(3.1)$ \\
Mucinous cystadneocarcinoma & $1(1.5)$ \\
Mixed germ cell tumor & $1(1.5)$ \\
Immature teratoma & $5(7.7)$ \\
\hline
\end{tabular}

Ovarian surgeries included cystectomy, oophorectomy, unilateral salpingo-oophorectomy, unilateral salpingo-oophorectomy with contralateral ovarian biopsy, and bilateral salpingo-oophorectomy via laparotomy. Table 4 shows the surgical methods. Of the 51 patients with benign tumors, including non-neoplastic lesions and benign cysts, 26 (51\%) underwent cystectomy, 6 (11.8\%) underwent oophorectomy, and 17 (33.3\%) underwent unilateral salpingo-oophorectomy, and none underwent bilateral salpingo-oophorectomy. Of the 14 patients with ma- 
lignant tumors, $2(14.3 \%)$ underwent bilateral salpingo-oophorectomy, 7 (50\%) underwent unilateral salpingo-oophoretomy, $2(14.3 \%)$ underwent oophorectomy, and $2(14.3 \%)$ underwent cystectomy. Half of the patients with benign tumors underwent conservative operations otherwise, half of the patients with malignant tumor underwent unilateral salpingo-oophorectomy $(p=0.0135)$. Table 5 shows the differences in initial symptoms between the patients with benign tumors and those with malignant tumors $(p=0.0077)$. In all patients with benign tumors, abdominal pain was the most common symptom $(56.9 \%)$, followed by palpable abdominal masses $(21.6 \%)$. However, in all patients with malignant tumors, abdominal palpable mass $(35.7 \%)$ and abdominal distension $(35.7 \%)$ were most common symptoms. The frequency of abdominal pain was higher in patients with malignant tumors than in those with benign tumors (14.3\% versus $56.9 \%)$.

Fourteen patients had malignant tumors in our series (Table 6). Of the 14 patients 4 had a palpable abdominal mass, 7 complained of abdominal distension, 2 complained of abdominal pain, and 1 patient had a vaginal bleeding. The tumor stages ranged between Ia and IIIc. Two patients with yolk sac tumors and 1 patient with an immature tertoma had elevated aFP. Five patients (1 patient with a granulosa cell tumor, 2 patients with immature teratomas, 1 patient with a yolk sac tumor, and 1 patient with a mucinous cystadenocarcinoma) had nonspecificlly elevated CA125. Nine patients underwent unilateral salpingo-oophorectomy, 4 patients simultaneously underwent omentectomy due to adherence of the omentum to the tumor. Two patients underwent total hysterectomy along with bilateral salpingo-oophorectomy and pelvic lymph node dissection due to suspicions of advanced cancer. One patient with a yolk sac tumor (case 4) underwent a total hysterectomy along with bilateral salpingo-oophorectomy and pelvic lymph node dissection. The patient did not receive any adjuvant therapy after 1 cycle of combination chemotherapy using cisplatin and etoposide because she had severe nausea and vomiting and because her parents desired to stop further treatment. The tumor recurred in the lungs 2 years later and she died 1 month after recurrence. The other patient with a yolk sac tumor (case 11) underwent a right adnexectomy along with a partial omentectomy and contralateral ovarian biopsy. After surgery, she received 6 cycles of combination chemotherapy using cisplatin and etoposide but did not respond well and died 4 months after the operation. One patient with a mixed germ cell tumor (case 14) composed of yolk sac tumor and dysgerminoma had an unresectable advanced tumor which had adhere to the adjacent structures. Debulking of the tumor was carried out and postoperative multiple drug chemotherapy using etoposide and carboplatin (EC) was started. She received 3 cycles of the chemotherapy but responded poorly to the chemotherapy in that the tumor progressed as evaluated by CT. The patient received additional sessions of chemotherapy using cisplatin-cytoxan and carboplatin-taxol; however, the tumor continued to progress and she died 6 months after diagnosis. Five patients with immature teratomas underwent unilateral salpingo-oophorectomy and received combination chemotherapy. Of the 4 patients, 3 received chemotherapy using platinum and etoposide, and 1 received chemotherapy using vincristine, adriamycin D, and cyclophosphamide, and 1 patient (case 13) received no adjuvant therapy. All of them have been free of disease. Of the 3 patients with dysgerminomas, 2 underwent unilateral therapy salpingo-oophorectomy and 1 underwent ovarian cystectomy. They received no adjuvant therapy, and were free of disease. Oophorectomy was a common operative procedure $(n=37,56.9 \%)$ as compared with ovarian cystectomy $(n=28,43.1 \%)$. All patients underwent laparotomy.

Table 4. Types of surgery in the patients with benign tumors, including non- neoplastic lesions, and those with malignant tumors.

\begin{tabular}{|c|c|c|c|c|c|c|}
\hline \multicolumn{7}{|c|}{ Type of surgery } \\
\hline \multirow{2}{*}{$\begin{array}{l}\text { Histologic } \\
\text { type }\end{array}$} & \multicolumn{5}{|c|}{ No. of patients (\%) } & \multirow[t]{2}{*}{ Total } \\
\hline & Cystectomy & Oophorectomy & $\begin{array}{l}\text { Unilateral salpin- } \\
\text { go-oophorectomy }\end{array}$ & $\begin{array}{l}\text { Unilateral salpingo-oophorectomy } \\
\text { +Contralateral ovary biopsy }\end{array}$ & $\begin{array}{l}\text { Bilateral salpin- } \\
\text { go-oophorectomy }\end{array}$ & \\
\hline Benign & $26(51.0)$ & $6(11.8)$ & $17(33.3)$ & $2(3.9)$ & 0 & $51(100)$ \\
\hline Malignant & $2(14.3)$ & $2(14.3)$ & $7(50.0)$ & $1(7.1)$ & $2(14.3)$ & $14(100)$ \\
\hline Total & $28(43.1)$ & $8(12.3)$ & $24(36.9)$ & $3(4.6)$ & $2(3.1)$ & $65(100)$ \\
\hline
\end{tabular}

$P=0.0135$ by Fisher's exact test 
Table 5. Comparison of initial symptoms between the patients with benign tumors and those with malignant tumor.s

\begin{tabular}{llll}
\hline Symptom and Sign & \multicolumn{1}{c}{ Benign } & Malignant & \multicolumn{2}{c}{-value $^{*}$} \\
\cline { 2 - 3 } & No. of patients (\%) & 0.0061 \\
\hline Abdominal pain & $29(56.9)$ & $2(14.3)$ & 0.2764 \\
Abdominal mass & $11(21.6)$ & $5(35.7)$ & 1.0000 \\
Incidental finding & $3(5.9)$ & 0 & 1.0000 \\
Prenatal sono finding & $1(2.0)$ & 0 & 1.0000 \\
Vaginal bleeding & $3(5.9)$ & $1(7.1)$ & 0.3870 \\
Urination/defecation difficulty & $1(2.0)$ & $1(7.1)$ & 0.0091 \\
Abdominal distension & $3(5.9)$ & $5(35.7)$ & $\mathbf{1 4 ( 1 0 0 )}$ \\
Total & $\mathbf{5 1 ( 1 0 0 )}$ & \\
\hline
\end{tabular}

" $p$-values are obtained by Fisher's exact test. $p=0.0077$ by Fisher's exact test.

Table 6. Summary of the patients with malignant tumors.

\begin{tabular}{|c|c|c|c|c|c|c|c|c|}
\hline Patients & $\begin{array}{l}\text { Age at } \\
\text { diagnosis }\end{array}$ & Symptom & Histologic type & Operation & Stage & Adjuvant treatment & Outcome & Tumor marker \\
\hline 1. & $9 y r s$ & $\begin{array}{l}\text { Vaginal bleed- } \\
\text { ing }\end{array}$ & $\begin{array}{l}\text { Juvenile granu- } \\
\text { losa cell tumor }\end{array}$ & $\begin{array}{l}\text { Lt ovary cys- } \\
\text { tectomy }\end{array}$ & Ia & None & NED & $\beta$-hcg $<2$ \\
\hline 2 & $12 \mathrm{yrs}$ & $\begin{array}{l}\text { Abdominal } \\
\text { distension }\end{array}$ & $\begin{array}{l}\text { Immature tera- } \\
\text { toma }\end{array}$ & Lt Ad & Ic & Carboplatin-VP16 & NED & $\begin{array}{l}\beta \text {-hcg<2, } \\
\text { CA-125:58 }\end{array}$ \\
\hline 3 & $14 y r s$ & $\begin{array}{l}\text { Abdominal } \\
\text { distension }\end{array}$ & $\begin{array}{l}\text { Juvenile granu- } \\
\text { losa cell tumor }\end{array}$ & $\begin{array}{l}\text { Rt Ad, PLND, } \\
\text { partial } \\
\text { omentectomy }\end{array}$ & Ia & Carboplatin-VP16 & NED & $\begin{array}{l}\text { aFP:21 } \\
\text { CA125:258,B-hcg<2, }\end{array}$ \\
\hline 4 & $14 y r s$ & $\begin{array}{l}\text { Abdominal } \\
\text { distension }\end{array}$ & Yolk sac tumor & $\begin{array}{l}\text { T/H, both Ad, } \\
\text { PLND }\end{array}$ & Ic & None & $\begin{array}{l}\text { Recur at } \\
\text { lung, 2yrs } \\
\text { later, EOD }\end{array}$ & $\begin{array}{l}\text { CA125: } \\
244, \\
\text { aFP: } 2125\end{array}$ \\
\hline 5 & $14 y r s$ & $\begin{array}{l}\text { Abdominal } \\
\text { distension }\end{array}$ & $\begin{array}{l}\text { Mucinous cyst } \\
\text { adenoca }\end{array}$ & Lt Ad & Ic & None & NED & $\begin{array}{l}\text { CA125: } \\
102 \\
\text { CA19-9:19 }\end{array}$ \\
\hline 6 & $8 y r s$ & $\begin{array}{l}\text { Abdominal } \\
\text { distension }\end{array}$ & $\begin{array}{l}\text { Immature tera- } \\
\text { toma }\end{array}$ & $\begin{array}{l}\text { Rt oophorec- } \\
\text { tomy, partial } \\
\text { omentectomy }\end{array}$ & Ic & Cisplatin-VP16 & NED & $\begin{array}{l}\text { CA125:69, } \\
\text { CA19-9:185, aFP: } 83\end{array}$ \\
\hline 7 & $10 y r s$ & $\begin{array}{l}\text { Abdominal } \\
\text { distension }\end{array}$ & $\begin{array}{l}\text { Immature tera- } \\
\text { toma }\end{array}$ & Lt Ad & Ia & Cisplatin- VP16 & NED & $\begin{array}{l}\text { CA125: } \\
\text { 9.4 } \\
\text { CA19-9:10, } \\
\beta-\text { hcg<2, }\end{array}$ \\
\hline 8 & $13 y r s$ & $\begin{array}{l}\text { Abdominal } \\
\text { pain, torsion }\end{array}$ & dysgerminoma & Rt Ad & Ia & None & NED & - \\
\hline 9 & $8 y r s$ & Palpable mass & dysgerminoma & Lt Ad & Ia & None & NED & - \\
\hline 10 & $11 \mathrm{yrs}$ & Palpable mass & dysgerminoma & $\begin{array}{l}\text { Rt ovary cys- } \\
\text { tectomy }\end{array}$ & Ia & None & NED & - \\
\hline 11 & $12 \mathrm{yrs}$ & $\begin{array}{l}\text { Constipation, } \\
\text { abdominal } \\
\text { distension }\end{array}$ & $\begin{array}{l}\text { Endodermal } \\
\text { sinus tumor }\end{array}$ & $\begin{array}{l}\text { Rt Ad, partial } \\
\text { omentectomy, } \\
\text { rectal serosal } \\
\text { biopsy, Lt ovary } \\
\text { biopsy }\end{array}$ & IIc & Cisplatin-VP16 & EOD & $\begin{array}{l}\text { aFP : } \\
2450\end{array}$ \\
\hline 12 & $12 \mathrm{yrs}$ & Palpable mass & $\begin{array}{l}\text { Immature tera- } \\
\text { toma }\end{array}$ & $\begin{array}{l}\text { Lt Ad, omental } \\
\text { biopsy, Lt peri- } \\
\text { toneal biopsy }\end{array}$ & Ic & $\begin{array}{l}\text { Vincristine, adri- } \\
\text { amycin D, cyclo- } \\
\text { phosphamide +ERT }\end{array}$ & NED & - \\
\hline 13 & $7 y r s$ & $\begin{array}{l}\text { Abdominal } \\
\text { pain }\end{array}$ & $\begin{array}{l}\text { Immature tera- } \\
\text { toma }\end{array}$ & Lt Ad & Ia & None & NED & CA125:28,CA19-9:7.2 \\
\hline 14 & $13 y r s$ & Palpable mass & $\begin{array}{l}\text { Mixed germ cell } \\
\text { tumor(Yolk sac } \\
\text { tumor + dys- } \\
\text { germinoma) }\end{array}$ & $\begin{array}{l}\text { T/H, both Ad, } \\
\text { PLND, } \\
\text { omentectomy }\end{array}$ & IIIc & $\begin{array}{l}\text { carboplatin-Vp16, } \\
\text { Cisplatin-Cytoxan, } \\
\text { carboplatin-taxol }\end{array}$ & EOD & - \\
\hline
\end{tabular}




\section{Discussion}

Menarche starts with changes in hormones of the hypothalamus, pituitary gland, and ovaries. The mechanisms of these changes are as follows: during puberty, estradiol inhibition decreases in response to tonic luteinizing hormone (LH) secretion. Tonic LH secretion is stimulated independently of ovarian steroid control and then the inhibitory feedback response to estradiol on tonic LH secretion decreases [7]. Therefore, it is important to evaluate the characteristics of ovarian masses which develop during puberty. Menarche occurs at the age between 9.1 and 17.7 years of age and at a mean age of 13 years [8]. In our study, patients ranged in age from 1 month to 14 years, with a mean age of $9.6 \pm 3.3$ years at the time of surgery.

Adnexal masses in premenarchal patients can manifest in many ways. Patients with adnexal masses may have acute abdominal pain which is difficult to differentiate from that of acute appendicitis. Such patients can also be referred with large palpable masses or abdominal distension. In this study, patients had abdominal pain $(47.7 \%)$, palpable abdominal masses $(24.6 \%)$, incidental ultrasonographic findings $(4.6 \%)$, and precocious puberty $(6.2 \%)$. Our results were similar to those of previous studies which reported that primary initial symptoms requiring surgeries were abdominal pain (48\%-56\%), abdominal palpable mass (9\%-22\%), incidental ultrasonographic findings $(5 \%-15 \%)$ and precocious puberty $(2 \%-7 \%)[1,4]$. It is thought that abdominal pain is the most common symptom of premenarchal ovarian masses. In our study, the indications for abdominal pain were ovarian torsion $(77.4 \%)$, ovarian cyst rupture $(3.2 \%)$ and others (19.4\%). Approximately $37 \%$ of our patients who required operations had ovarian torsion.

In pediatric patients, a longer infundibulopelvic ligament leads to ovarian torsion more frequently [6]. Ovarian torsion is more common on the right side and thus many patients with ovarian torsion can be misdiagnosed with acute appendicitis before surgery [9, 10]. It is still controversial whether the sigmoid colon helps prevent left adnexal torsion or whether left lesions are more commonly missed and managed nonsurgically $[1,11]$. Treatment methods for ovarian torsion have changed; in the past, salpingo-oophorectomy was the treatment of choice. Historically, detorsion of the ovary has been avoided to prevent the theoretical risk of pulmonary embolisms from the infundibulopelvic vein [12]. More recently, investigators have conducted detorsion and preservation of the ovary even when the ovary appears markedly necrotic $[13,14]$. Ovarian function has been shown to recover after detrosion in adults [11]. Cohen et al. [13] reported that, as assessed by ultrasonography, $93 \%$ of the necrotic or bluish ovaries were restored to normal ovarian function 3 months after detorsion and preservation of the ovaries. In our study, $42 \%$ of the patients with ovarian torsion underwent detorsion and more conservative surgeries. Preservation of future fertility is important in the surgical treatment of premenarchal girls. Surgical management of benign masses and functional cysts should be conservative and mainly includes ovarian cystectomy or simple excision of the lesions.

Although technically difficult, treatment methods minimize the risk of subsequent infertility and help conserve as much normal ovarian tissue as possible in order to maintain reproductive and endocrine functions. In our study, in the treatment of benign tumors and functional cysts, the ovaries were completely removed in 25 patients $(49 \%)$. Of these 25 patients, 19 underwent unilateral resection of the fallopian tube $(37 \%)$ and $2(3.9 \%)$ only underwent biopsy. All of our patients were treated by laparotomy.

Breen et al. [15] reported that $64 \%$ of the ovarian masses found in children and adolescents were neoplastic, while $36 \%$ were non-neoplastic. Van Winter et al. [16] stated that in children and adolescents under the age of 20 years, $64.3 \%$ of the ovarian masses were non-neoplastics, $27.6 \%$ were benign, and $8.1 \%$ were malignant. In our study, we found that $10.8 \%$ of the ovarian masses were non-neoplastic, $67.7 \%$ were benign, and $21.5 \%$ were malignant. Germ cell tumors were the most common among the pediatric ovarian neoplasms. In children, the frequency of germ cell tumors varies from $67 \%$ to $85 \%$ [1, 12, 17-19]. Among them, teratoma is the most common form and constitutes $60 \%-73 \%$ of all ovarian tumors, of which $15 \%$ are malignant $[5,12,20]$. In our study, $79.2 \%$ of the germ cell tumors were mature teratomas, $9.4 \%$ were immature teratomas, and $5.7 \%$ were dysgerminomas. Sex cord tumors, which are derived from ovarian stroma, can also develop in premenarcheal girls. They constitute $10 \%-25 \%$ of all pediatric ovarian neoplasms. Granulosa cell tumors are the most common form and are associated with hyperestrogenism or precocious puberty $[5,12,20]$. In our study, $3.4 \%$ of all ovarian masses and $14.3 \%$ of all ovarian malignant tumors were granulosa cell tumors. Among the patients with granulose cell tumors, 1 patient (50\%) showed pseudoprecocity, but the other did not. Unlike in adult patients, the incidence of ovarian tumors is lower in children than in adults. In adults, $80 \%$ of the ovarian tumors are of epithelial origin. In children, $7 \%-20 \%$ of the ovarian tumors are of epithelial origin $[1,5,20,21]$. In our study, $1.7 \%$ of the ovarian masses 
and $7.1 \%$ of the malignant ovarian tumors were of epithelial origin. If malignancies were suspected by frozen section examination, the patients underwent staging operations and were treated with combination chemotherapy. Fourteen patients were diagnosed with malignant tumors. Four patients underwent staging operations and 7 patients were treated with chemotherapy. Three patients died, but the remaining patients have had uneventful courses so far.

\section{Conclusion}

In conclusion, premenarchal girls with ovarian masses may have variable symptoms. Abdominal pain is the most common symptom. The incidences of abdominal distension and palpable masses were higher in patients with malignant tumors than in those with benign tumors $(5.9 \%$ versus $35.7 \%, 21.6 \%$ versus $35.7 \%$ ). Unlike in adults, ovarian tumors of premenarchal girls generally originate from the germ cell line and treatments have relatively good prognoses even when the tumors are malignant. Epithelial and sex cord-stromal tumors are relatively uncommon in children and their clinical behaviors are unpredictable.

This is a regional study, so it may not be applicable to the general population. We assessed clinical features, operative outcomes, and histological classification in Korean premenarchal girl with ovarian masses. Further studies with a larger number of subjects are needed to confirm our results.

\section{Competing Interests}

The authors have declared that no competing interest exists.

\section{References}

1. Cass DL, Hawkins E, Brandt ML, et al. Surgery for ovarian masses in infants, children, and adolescents: 102 consecutive patients treated in a 15-year period. J Pediatr Surg. 2001; 36(5): 693-9.

2. Piippo S, Mustaniemi L, Lenko H, Aine R, Maenpaa J. Surgery for ovarian masses during childhood and adolescence: A report of 79 cases. J Pediatr Adolesc Gynecol. 1999; 12: 223-7.

3. Brown MF,Hebra A, McGeehin K, Ross AJ 3rd, Ovarian masses in children: A review of 91 cases of malignant and benign masees. Journal of pediatric surgery. 1993; 28(7): 930-2.

4. Ryoo U, Lee DY, Bae DS, Yoon BK, Choi D. Clinical characteristics of adnexal masses in Korean children and adolescents: retrospective analysis of 409 cases. J Minim Invasive Gynecol. 2010;17(2): 209-13.

5. Al Jama FE, Al Ghamdi AA, Gasim T, Al Dakhiel SA, Rahman J, Rahman MS. Ovarian tumors in children and adolescents--a clinical study of 52 patients in a university hospital. J Pediatr Adolesc Gynecol. 2011; 24(1): 25-8.

6. Shim SI, Hur SY, et al. Clinicopathological observation on ovarian tumors in premenarcheal years. Kor J Obstet Gynecol. 1998; 41(8): 2072-9.

7. Foster DL, Ryan KD. Endocrine mechanisms governing transition into adulthood: A marked decrease in inhibitory feedback action of estradiol on tonic secretion of luteinizing hormone in the lamb during puberty. Endocrinology. 1979; 105(4): 896-904.

8. Harlan WR, Harlan EA.Grillo GP, Secondary sex characteristics of girls 12 to 17 years of age : the US health examination survey. J Pediatr. 1980; 96(6):1074-8.
9. Schmahmann S, Haller JO. Neonatal ovarian cysts: pathogenesis, diagnosis and mangement. Rediatr Radiol. 1997;27(101-105): 101-5.

10. Brandt ML, Luks Fl, Filiatrault D, Garel L, Desjardins JG, Youssef S. Surgical indications in antenatally diagnosed ovarian cysts. J Pediatr Surg. 1991; 26(3): 276-82.

11. Quint EH, Smoth YR. Ovarian surgery in premenarchal girls. J Pediatr Adolesc Gynecol. 1999; 12: 27-9.

12. Skinner MA, Schlatter MG, Heifetz SA, Grosfeld JL. Ovarian neoplasms in children. Arch Surg. 1993;128: 849-54.

13. Cohen SB, Oelsner G, Seidman DS, Admon D, Mashiach S, Goldenberg M. Laparoscopic detorsion allows sparing of the twisted ischemic adnexa. J Am Assoc Gynecol Laparosc. 1999; 6(2): 139-43.

14. Eckler K, Laufer MR, Perlman SE. Conservative management of bilateral asynchronous adnexal torsion with necrosis in a prepubescent girl. J Pediatr Surg. 2000; 35(8): 1248-51.

15. Breen JL, Maxson WS. Ovarian tumors in children and adolescents. Clin Obstet Gynecol. 1997; 20(3): 607-23.

16. van Winter JT, Simmons PS, Podratx KC. Surgically treated adnexal masses in infancy, childhood, and adolescence. Am J Ostet Gynecol.1994; 170(6): 1786- 9 .

17. Ehren IM, Mahour GH, Isaacs H Jr. Benign and malignant ovarian tumors in children and adolesents: A review of 63 cases. Am J Surg. 1984;147: 339-44

18. Gribbon M, Ein SH, Mancer K. Pediatric malignant ovarian tumors: A 43-year review. J Pediatr surgery. 1992; 27(4):480-4.

19. Morris HB, La V, Draper GJ. Malignant epithelial tumors of the ovary in childhood: A Clinicopathological study of 13 cases in Great Britain 1962-1978. Gynecol Oncol. 1984;19: 290-7.

20. Moss EH, Carty H, Sprigg A. A retrospective study of large ovarian masses in paediatric practice. Eur J Radiol. 1993; 17(3): 159-65.

21. Morowitz M, Huff D, von Allmen D. Epithelial ovarian tumors in children: a retrospective analysis. J Pediatr Surg. 2003; 38(3): 331-5. 